\title{
VIEWPOINT
}

\section{Critical illness-induced dysglycaemia: diabetes and beyond}

\author{
Fang Gao Smith', Ann M Sheehy ${ }^{2}$, Jean-Louis Vincent ${ }^{3}$ and Douglas B Coursin ${ }^{4 *}$
}

\begin{abstract}
Type 2 diabetes has reached epidemic proportions in many parts of the world. The disease is projected to continue to increase and double within the foreseeable future. Dysglycaemia develops in the form of hyperglycaemia, hypoglycaemia and marked glucose variability in critically ill adults whether they are known to have premorbid diabetes or not. Patients with such glucose dysregulation have increased morbidity and mortality. Whether this is secondary to cause and effect from dysglycaemia or is just related to critical illness remains under intense investigation. Identification of intensive care unit (ICU) patients with unrecognised diabetes remains a challenge. Further, there are few data regarding the development of type 2 diabetes in survivors after hospital discharge. This commentary introduces the concept of critical illness-induced dysglycaemia as an umbrella term that includes the spectrum of abnormal glucose homeostasis in the ICU. We outline the need for further studies in the area of glucose regulation and for follow-up of the natural history of abnormal glucose control during ICU admission and beyond.
\end{abstract}

Type 2 diabetes is one of the greatest challenges facing healthcare professionals. The general population disease prevalence is approximately $2.8 \%$ worldwide [1]. In contrast, the most recent US National Health and Nutrition Examination Survey estimates that $12.9 \%$ of US ambulatory adults over 20 years of age have type 2 diabetes [2]. The prevalence of diabetes is expected to double over the next 30 years due to increased age, inactivity and obesity [1].

Complicating this phenomenon is the knowledge that approximately $40 \%$ of patients with diabetes remain

*Correspondence: dcoursin@wisc.edu

${ }^{4}$ Department of Anesthesiology and Medicine, University of Wisconsin School of Medicine and Public Health, B6/319 UW CSC, Madison, WI 53792-3272, USA

Full list of author information is available at the end of the article undiagnosed [2]. These patients cannot be treated, and are vulnerable to short-term and long-term complications [3-5]. The true prevalence of diabetes in hospitalised patients is not known, due to the heterogeneous patient population and limitations in diagnostic tests [6]. The prevalence in intensive care unit (ICU) patients is perhaps $25 \%$ or higher, depending on unit specialty and patient demographics [6].

Adults with diabetes have at least double the annual mortality compared with adults without diabetes [7]. Paradoxically, several studies of hospitalised patients have demonstrated that hyperglycaemic individuals without known diabetes have significantly greater morbidity and mortality than either patients with known diabetes or those with normal glucose tolerance [8-11]. Hyperglycaemic patients without diabetes include those with undiagnosed diabetes, prediabetes (impaired fasting glucose and impaired glucose tolerance) or stressinduced hyperglycaemia ( $\mathrm{SIH}$ - defined as patients with elevated blood glucose that reverts to normal after illness subsides and counterregulatory hormone and inflammatory mediator surge abates [6]. Large, retrospective studies in critically ill adults have shown that hyperglycaemic patients with diabetes have lower ICU and hospital mortality and shorter length of ICU stay than critically ill hyperglycaemic patients without diabetes [8-10]. This increased mortality in hyperglycaemic patients without diabetes occurs despite this population having lower absolute glucose levels than those with diabetes. Similar findings were reported in hospitalised general care patients [11].

How can this paradox be explained? First, patients without diabetes may have unexpected hyperglycaemia that is frequently left untreated. Umpierrez and colleagues showed that insulin therapy was provided to $77 \%$ of patients with known diabetes, compared with $35 \%$ of hyperglycaemic patients without diabetes [11]. Second, the critically ill nondiabetic hyperglycaemic population comprises patients with undiagnosed diabetes and patients with SIH $[6,12]$. Whether hyperglycaemia and adverse outcomes in the nondiabetic cohort are due to $\mathrm{SIH}$, or are simply a marker of severity of illness, remains unknown. Prospective studies with clearly defined 
Table 1. Factors impacting critical illness-induced dysglycaemia

Continued growth of abnormal glucose homeostasis in adults

Heterogeneous intensive care unit patient population

Uncertainty as to whether hyperglycaemia may cause adverse outcomes, or may simply be the effect of counterregulatory hormone surge indicating severity of illness

Need for further clarification of the incidence of co-existing factors in the development of and role of hypoglycaemia (<80 mg/dl) on intensive care unit outcome

Ongoing debate over the ideal method and frequency of glucose measurement, the optimal glucose level to maintain in adult intensive care unit populations, and the modulation of glucose variability

nondiabetic cohorts are needed to differentiate between undiagnosed diabetes and SIH.

Accurately diagnosing hyperglycaemic ICU patients with new diabetes while they are still hospitalised, however, remains difficult. Fasting plasma glucose values and oral glucose tolerance tests can only be used in ICU survivors after discharge, as these tests are inaccurate during critical illness [6,12]. Recently endorsed by the International Expert Committee [13] and the American Diabetes Association as a diagnostic criterion for diabetes mellitus [14], haemoglobin $A_{1 c}$ may prove useful in categorising inpatients [15]. But haemoglobin $\mathrm{A}_{1 \mathrm{c}}$ must be used carefully, as it may be inaccurate in conditions that shorten or prolong the survival of erythrocytes and in patients receiving blood transfusions [13]. Likewise, its value may vary by racial or ethnic group [16]. Ambulatory follow-up at 6 to 8 weeks post recovery affords the best opportunity to look back and diagnose type 2 diabetes [12].

Owing to these limitations, few studies have attempted to define the true prevalence of diabetes in ICU patients with unexpected inpatient hyperglycaemia. Recently, Mullhi and colleagues showed in ICU survivors $(n=30)$ with new hyperglycaemia that $46.7 \%(n=14)$ had undiagnosed diabetes and $30 \%$ had a prediabetes state $(n=9$ impaired fasting glycaemia or glucose tolerance) during their ICU stay [17]. Similarly, the natural history of ICU patients with inpatient hyperglycaemia but without diabetes merits further study. Gornik and colleagues recently reported that $15.2 \%$ of septic ICU patients with documented SIH and normal, post-discharge glucose tolerance developed diabetes within 5 years of hospital discharge, versus $4.2 \%$ of normoglycaemic ICU patients [18]. The authors hypothesised that stress may uncover latent metabolic disturbance. Gornik and colleagues presented very similar findings in Critical Care about the development of type 2 diabetes in $17.1 \%$ of patients with SIH among nearly 600 heterogeneous critically ill patients followed for 5 years after ICU discharge [19]. These longitudinal data reveal the importance of continued surveillance of this high-risk population.

Inpatients may also experience other types of glucose dysregulation. Large, randomised controlled trials from the past decade, which investigated the impact of preventing pronounced hyperglycaemia during critical illness with insulin infusion, report increased mortality associated with hypoglycaemia [20-23]. Egi and colleagues showed that increased mortality in mildly hypoglycaemic patients (blood glucose $<80 \mathrm{mg} / \mathrm{dl}$ ) may be independent of insulin use [21]. Their findings suggest that altered glucose metabolism, as well as exogenous overtreatment with insulin, may play a meaningful role in critical illness and mortality. In a retrospective cohort analysis of 7,820 patients with acute myocardial infarction, Kosiborod and colleagues reported that patients who developed spontaneous hypoglycaemia had an increased mortality while those who developed it secondary to insulin therapy did not [24]. Several studies have also demonstrated increased mortality with either hypoglycaemia or hyperglycaemia [20,21]. Glucose variability may confer an adverse risk of mortality, independent of absolute glucose level [23] - although recently the Leuven group retrospectively analysed their two large prospective glucose control trials, and determined that the reduced mortality observed with intensive insulin therapy in the trials was not attributable to an effect on blood glucose variability [25]. The accompanying editorial by Krinsley, however, raised additional factors such as frequency of hypoglycaemia and method of glucose measurement that may have influenced these findings [26]. Limitations in existing glucose monitoring technology further complicate the above issues. This difficulty cannot be ignored when applying protocols to control and regulate blood glucose [27].

We suggest a broader view of glucose dysregulation in the critically ill patient based on numerous factors (Table 1). We apply the term critical illness-induced dysglycaemia to patients with hyperglycaemia, hypoglycaemia or glucose variability. Patients without diabetes, but with other features of critical illness-induced dysglycaemia, appear to be at risk to develop overt type 2 diabetes. These patients should undergo longitudinal evaluation and intervention for the development of subsequent type 2 diabetes.

The decade ending in 2009 witnessed an explosion in publications about ICU glycaemic control, beginning 
with the landmark Leuven trial in 2001 [28]. Formal recommendations in 2004 endorsed tight glycaemic control [29]. The decade ended with the 2009 publication of the NICE-SUGAR study [22], and less stringent critical care glucose control guidelines [30]. The concept of critical illness-induced dysglycaemia encompasses all of these factors. We issue a call to recognise the heterogeneous inpatient hypoglycaemic or hyperglycaemic population, in order to study hyperglycaemic subpopulations, to determine diagnostic alternatives for diagnosis of unrecognised inpatients with diabetes, and to develop better monitoring and application of safe, closed-loop systems.

\section{Abbreviations}

ICU, intensive care unit; SIH, stress-induced hyperglycaemia.

\section{Competing interests}

The authors declare that they have no competing interests.

\section{Author details}

'Department of Anaesthesia, Critical Care and Pain, University of Warwick, Heart of England NHS Trust, Health Sciences Research Institute, Room

A-102, Clinical Trial Unit, Warwick Medical School, Coventry, CV4 7AL, UK.

${ }^{2}$ Department of Medicine, University of Wisconsin School of Medicine and Public Health, 3126 Centennial Building, 1685 Highland Ave, Madison, WI 53705, USA. ${ }^{3}$ Department of Intensive Care, Erasmus University, Route de Lennik 808-B-1070, Brussels, Belgium. ${ }^{4}$ Department of Anesthesiology and Medicine, University of Wisconsin School of Medicine and Public Health, B6/319 UW CSC, Madison, WI 53792-3272, USA.

Published: 5 November 2010

\section{References}

1. Wild S, Roglic G, Green A, Sicree R, King H: Global prevalence of diabetes: estimates for the year 2000 and projections for 2030. Diabetes Care 2004, 27:1047-1053.

2. Cowie CC, Rust KF, Ford ES, Eberhardt MS, Byrd-Holt DD, Li C, Williams DE, Gregg EW, Bainbridge KE, Saydah SH, Geiss LS: Full accounting of diabetes and pre-diabetes in the U.S. population in 1988-1994 and 2005-2006. Diabetes Care 2009, 32:287-294.

3. Chalmers J, Cooper ME: UKPDS and the legacy effect. N Engl J Med 2008, 359:1618-1620.

4. Holman RR, Paul SK, Bethel MA, Matthews DR, Neil HA: 10-year follow-up of intensive glucose control in type 2 diabetes. N Engl J Med 2008, 359:1577-1589.

5. Sheehy AM, Coursin DB, Gabbay RA: Back to Wilson and Jungner: 10 good reasons to screen for type 2 diabetes mellitus. Mayo Clin Proc 2009, 84:38-42.

6. Clement S, Braithwaite SS, Magee MF, Ahmann A, Smith EP, Schafer RG, Hirsch IB: Management of diabetes and hyperglycemia in hospitals. Diabetes Care 2004, 27:553-591.

7. World Health Organization facts [http://www.who.int/mediacentre/ factsheets/fs312/en/index.html]

8. Egi M, Bellomo R, Stachowski E, French CJ, Hart GK, Hegarty C, Bailey M: Blood glucose concentration and outcome of critical illness: the impact of diabetes. Crit Care Med 2008, 36:2249-2255.

9. Rady MY, Johnson DJ, Patel BM, Larson JS, Helmers RA: Influence of individual characteristics on outcome of glycemic control in intensive care unit patients with or without diabetes mellitus. Mayo Clin Proc 2005, 80:1558-1567

10. Stegenga ME, Vincent JL, Vail GM, Xie J, Haney DJ, Williams MD, Bernard GR, van der Poll T: Diabetes does not alter mortality or hemostatic and inflammatory responses in patients with severe sepsis. Crit Care Med 2010, 38:539-545
11. Umpierrez GE, Isaacs SD, Bazargan N, You X, Thaler LM, Kitabchi AE: Hyperglycemia: an independent marker of in-hospital mortality in patients with undiagnosed diabetes. J Clin Endocrinol Metab 2002, 87:978-982

12. Sheehy AM, Gabbay RA: An overview of preoperative glucose evaluation, management, and perioperative impact. J Diabetes Sci Technol 2009, 3:1261-1269.

13. International Expert Committee report on the role of the $\mathrm{A} 1 \mathrm{C}$ assay in the diagnosis of diabetes. Diabetes Care 2009, 32:1327-1334.

14. Standards of medical care in diabetes -2010 . Diabetes Care 2010, 33(Suppl 1):S11-S61.

15. Braithwaite SS: Through the eyes of the A1C: a call to re-examine stress hyperglycemia. Crit Care Med 2010, 38:717-719.

16. Ziemer DC, Kolm P, Weintraub WS, Vaccarino V, Rhee MK, Twombly JG, Narayan KM, Koch DD, Phillips LS: Glucose-independent, black-white differences in hemoglobin A1c levels: a cross-sectional analysis of 2 studies. Ann Intern Med 2010, 152:770-777.

17. Mullhi D, Barnett A, Jones A, Gao F: The impact of abnormal glucose homeostasis on the outcome of intensive care patients. J Intensive Care Soc 2007, 8:28-30.

18. Gornik I, Vujaklija A, Lukic E, Madzarac G, Gasparovic V: Hyperglycemia in sepsis is a risk factor for development of type II diabetes. J Crit Care 2010, 25:263-269.

19. Gornik I, Vujaklija-Brajkovic A, Renar IP, Gasparovic V: A prospective observational study of the relationship of critical illness associated hyperglycaemia in medical ICU patients and subsequent development of type 2 diabetes. Crit Care 2010, 14:R130.

20. Bagshaw SM, Egi M, George C, Bellomo R: Early blood glucose control and mortality in critically ill patients in Australia. Crit Care Med 2009, 37:463-470.

21. Egi M, Bellomo R, Stachowski E, French CJ, Hart GK, Taori G, Hegarty C, Bailey M: Hypoglycemia and outcome in critically ill patients. Mayo Clin Proc 2010 85:217-224.

22. Finfer S, Chittock DR, Su SY, Blair D, Foster D, Dhingra V Bellomo R, Cook D, Dodek P, Henderson WR, Hébert PC, Heritier S, Heyland DK, McArthur C, McDonald E, Mitchell I, Myburgh JA, Norton R, Potter J, Robinson BG, Ronco $\mathrm{JJ}$ : Intensive versus conventional glucose control in critically ill patients. N Engl J Med 2009, 360:1283-1297.

23. Krinsley JS: Glycemic variability: a strong independent predictor of mortality in critically ill patients. Crit Care Med 2008, 36:3008-3013.

24. Kosiborod M, Inzucchi SE, Goyal A, Krumholz HM, Masoudi FA, Xiao L, Spertus JA: Relationship between spontaneous and iatrogenic hypoglycemia and mortality in patients hospitalized with acute myocardial infarction. JAMA 2009, 301:1556-1564.

25. Meyfroidt G, Keenan DM, Wang X, Wouters PJ Veldhuis JD, Van den Berghe G: Dynamic characteristics of blood glucose time series during the course of critical illness: effects of intensive insulin therapy and relative association with mortality. Crit Care Med 2010, 38:1021-1029.

26. Krinsley JS: Glycemic variability in critical illness and the end of Chapter 1. Crit Care Med 2010, 38:1206-1208.

27. Rice MJ, Pitkin AD, Coursin DB: Review article: glucose measurement in the operating room: more complicated than it seems. Anesth Analg 2010, 110:1056-1065.

28. van den Berghe G. Wouters P. Weekers F Verwaest C. Bruyninckx F. Schetz M, Vlasselaers D, Ferdinande P, Lauwers P, Bouillon R: Intensive insulin therapy in the critically ill patients. N Engl J Med 2001, 345:1359-1367.

29. Garber AJ, Moghissi ES, Bransome ED Jr, Clark NG, Clement S, Cobin RH, Furnary AP, Hirsch IB, Levy P, Roberts R, Van den Berghe G, Zamudio V; American College of Endocrinology Task Force on Inpatient Diabetes Metabolic Control: American College of Endocrinology position statement on inpatient diabetes and metabolic control. Endocr Pract 2004, 10:77-82.

30. Moghissi ES, Korytkowski MT, DiNardo M, Einhorn D, Hellman R, Hirsch IB, Inzucchi SE, Ismail-Beigi F, Kirkman MS, Umpierrez GE: American Association of Clinical Endocrinologists and American Diabetes Association consensus statement on inpatient glycemic control. Endocr Pract 2009, 15:353-369.

doi:10.1186/cc9266

Cite this article as: Smith FG, et al: Critical illness-induced dysglycaemia: diabetes and beyond. Critical Care 2010, 14:327. 